\title{
Moyses Chahon, Um dos Maiores Heróis Brasileiros Judeus da II Guerra Mundial
}

Moyses Chahon, One of the Greatest Brazilian Brazilian Heroes of World War II

$$
\begin{aligned}
& \text { Israel Blajberg } \\
& \text { iblaj@telecom.uff.br } \\
& \text { UFF - Universidade Federal Fluminense, TELECOM, Faculty Member } \\
& \text { Brasil }
\end{aligned}
$$

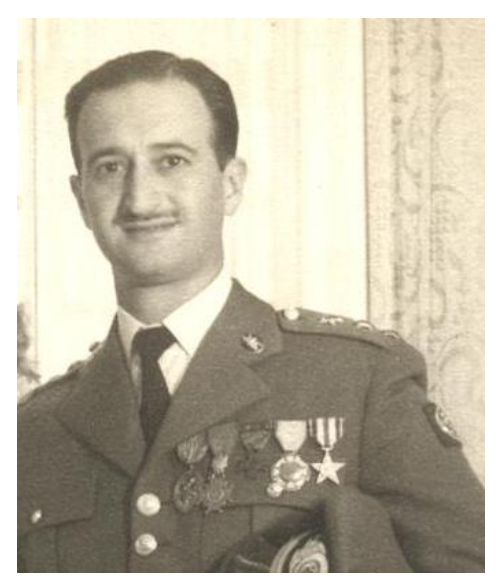

General de Divisão R/1 Moyses Chahon, Z"L (1918 - 1981)

\section{Resumen}

Este articulo trata de uno de los grandes Generales de División judio que participo en la II Guerra Mundial. La narración há sido hecha en base a información proporcionada por la família y recortes de prensa. El autor agradece a Vera e Jose Alberto Chahon y al Ten R/2 Israel Rosenthal

Palabras claves: Moyses Chaon, II Guerra Mundial, Brasil, judios en el ejercito brasileiro

\section{Abstract}

This article deals with one of the great Generals of the Jewish Division that participated in the Second World War. The narration has been made based on information provided by the family and 
press clippings. The author thanks Vera and Jose Alberto Chahon and the Ten R / 2 Israel Rosenthal.

Keywords: Moyses Chaon ,, World War II, Brazil, Jews in the Brazilian Army

O Brasil teve cerca de meia-centena de Heróis Brasileiros Judeus da II Guerra Mundial. O numero exato jamais será conhecido. Deus sabe os seus nomes. O assunto ficou adormecido durante décadas, sem que se soubesse quantos brasileiros de fé judaica que participaram das operações bélicas contra a Alemanha Nazista.

Até 2016 cerca de 50 nomes foram arrolados, representando um percentual elevado para a comunidade judaica da época, nucleada em imigrantes portanto dispensados do Serviço Militar.

Assim, foram os filhos desta geração de imigrantes que voluntariamente acorreram ao chamado da Pátria que acolhera seus pais e avós.

Moyses Chahon nasceu aos 27-8-1918 no Rio de Janeiro, filho de José Ascher Chahon e Mathilde Gammal. Em princípios do séc. XX, seus pais emigraram de Izmir, Turquia, pais onde florescia importante comunidade judaica, ha poucos anos vitima do ódio que dinamitou uma sinagoga.

Apos longa viagem de navio, a família foi morar na Rua do Rezende. Preferiram o Brasil, Pais do Futuro no dizer do correligionário Stefan Zweig, seguindo os passos de outros que haviam partido mais cedo em busca dos ares mais amenos do Novo Mundo.

Ali perto, Moyses estudou no Colégio Anglo-Americano na Praia de Botafogo, e depois no Colégio Pedro II (Internato). Cursou a Escola Militar do Realengo, praça de 28 abril 1939, tendo sido declarado Aspirante a Oficial da Arma de Infantaria aos 3 dez 1941. 


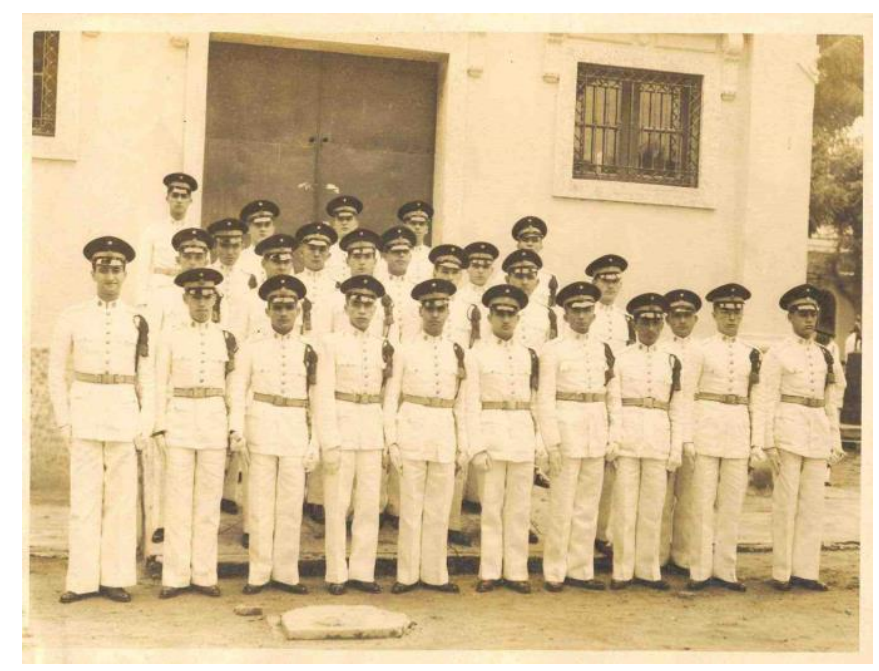

A foto mostra o Cadete Moyses ( $1^{\mathrm{a}}$. Fila, $1^{\mathrm{o}}$. à esquerda), por ocasião da sua formatura na Escola Militar do Realengo.

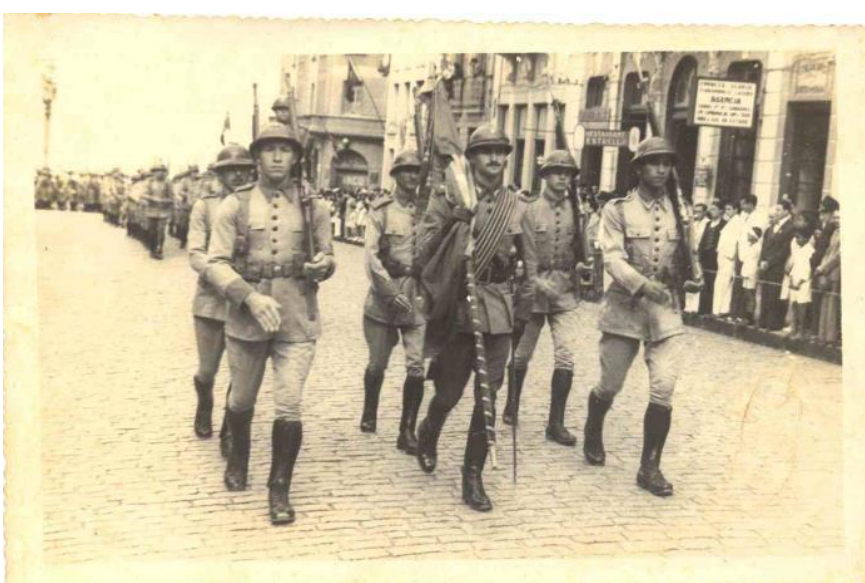

Em 1942 estava servindo em Florianópolis. $\mathrm{Na}$ foto ve-se Moyses desfilando na Parada de 7 de Setembro. Como oficial mais moderno, coube-lhe ser o porta-bandeira na Guarda de Honra.

Promovido a $1^{\circ}$. Tenente, foi transferido para o Rio, onde foi servir no Sampaio, o I Regimento de Infantaria, na Vila Militar.

Os jornais de Florianópolis em jan/1944 noticiavam os atos de promoção e transferência do Ministro da Guerra, já naquela época destacando suas qualidades promissoras, lamentando a sua ausência e referindo-se em termos bastante elogiosos.

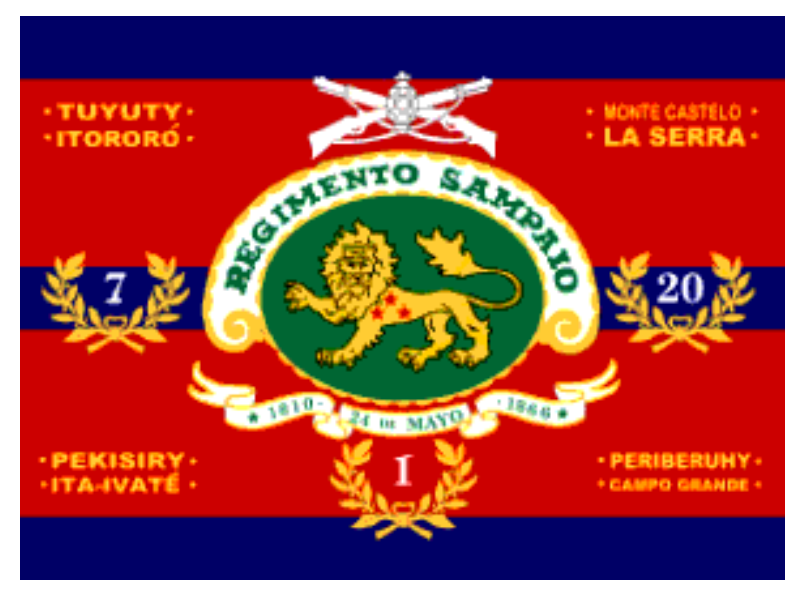

Embarcou para a Itália no 2. Escalão, aos 22 / set /1944. Na FEB foi incorporado a 6a. Companhia do Regimento, hoje o $1^{\circ}$. Batalhão de Infantaria Motorizada do Grupamento de Unidades Escola. 
Comandou um pelotão de fuzileiros, nos ataques a Monte Castelo em 12/12/1944 e em 21/02/1945; Conquistou as posições inimigas em La Serra - 24/02/1945;

De amarelecidos recortes de jornais zelosamente preservados pela Família pode-se reviver uma historia recoberta pela poeira do tempo. A emoção de ler hoje estes relatos é a mesma de exatos 60 anos, aos 24 de fevereiro de 1945, 3 dias após a Tomada do Monte Castelo.

Segundo despacho do correspondente de guerra Joel da Silveira, enviado especial da Agencia Meridional de algum ponto da Itália, ao cair da tarde os pelotões comandados pelos Tenentes Moyses Chahon e Apolo Miguel Rezk receberam ordem de avançar sobre os morros de La Serra. Após 6 horas de combate, a posição foi tomada, ficando feridos os Tenentes Apolo e Moyses. A valente conduta dos soldados sob pesado fogo alemão, tomando 2 pontos fortemente defendidos foi elogiada pelo Comandante do V Exercito Americano, devido a sua grande importância para as operações futuras.

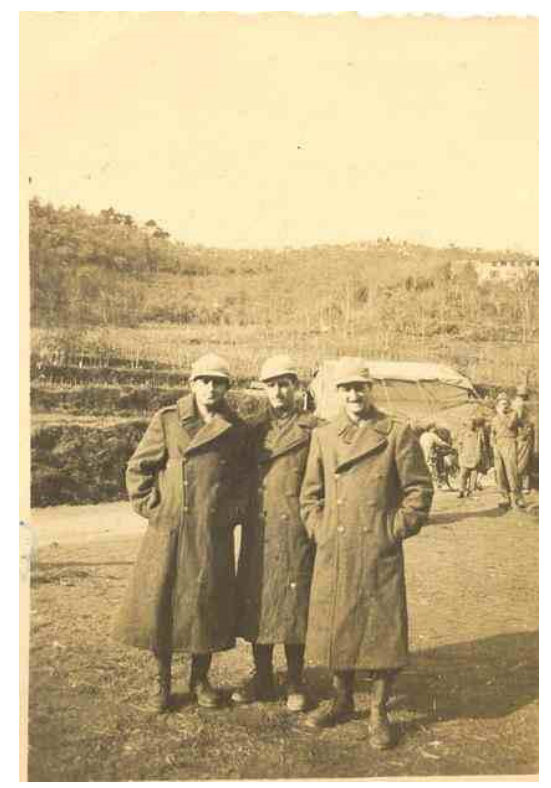

O Correio da Manhã sob a manchete É Carioca o Tenente Chahon divulga que ele tem 26 anos, filho de Matilde Chahon Gammal, o endereço na Av N. Sa. de Fátima, 86/501, e que esta senhora, alem do Ten Moyses, tem outro filho lutando pelo Brasil, o qual se chama Alberto e é tenente do Corpo de Transmissões.

Nesta foto, Moyses é o $1^{\circ}$. à direita, onde escreveu no verso:

11 de janeiro de 1945.

"Se os pensamentos transportassem os seres para onde estivessem voltados, estaria agora ai para beijar carinhosamente tuas faces, querida mãe."

Moises 
Ao final da guerra, em 23 de maio de 1945, ainda na Itália, na cidade de Alessandria, o Comandante do V Exercito Americano, Tenente General Lucian Truscott agraciou os soldados brasileiros da FEB e da FAB que mais se destacaram com as seguintes medalhas:

1 - Citação de Combate - Medalha "Distinguished Service Cross" (Cruz de Serviços Distintos) - APOLLO MIGUEL REZK (1G - 153466) - Primeiro Tenente R/2 de Infantaria

\section{2 - Citação de Combate - Medalha "Silver Star" (Estrela de Prata) -}

MOYSES CHAHON (1G-163.603) - Primeiro Tenente de Infantaria

GERVAZIO DESCHAMPS PINTO (1G-149.061) - Segundo Tenente de Infantaria JOAO GUILHERME SCHULTZ MARQUES (1G-243.180) - Primeiro Sargento de Infantaria AFONSO DE MELLO(1G-267.486) - Soldado de Infantaria

3 - Citação de Combate - Medalha "Bronze Star" (Estrela de Bronze) - concedida a 11 militares brasileiros, entre os quais os Tenente Coronéis Humberto de Alencar Castello Branco e Amaury Kruel, que um dia se tornariam Marechais do Exército Brasileiro.

4 - Citação de Combate - Medalha "Air Medal" (Medalha de Aeronáutica) - concedida a 20 pilotos de caça brasileiros,

Portanto, apenas 4 brasileiros receberam a Silver Star, entre os quais Moyses. A única Medalha de Serviços Distintos, mais alta condecoração americana, foi concedida a apenas um brasileiro, o Ten R/2 Apolo, conhecido justamente como o maior herói da FEB, e que comandava o outro pelotão da mesma $6^{\text {a }}$. Cia do Regimento Sampaio, junto com o pelotão de Moyses na Tomada de La Serra.

19.05.45 - Tem R/2 Apollo único brasileiro agaciado com a Cruz de Servicos Distintos, dos EE.UU., é condecorado pelo Gen. Truscott. Alessandria, Italia. 
Israel Blajberg

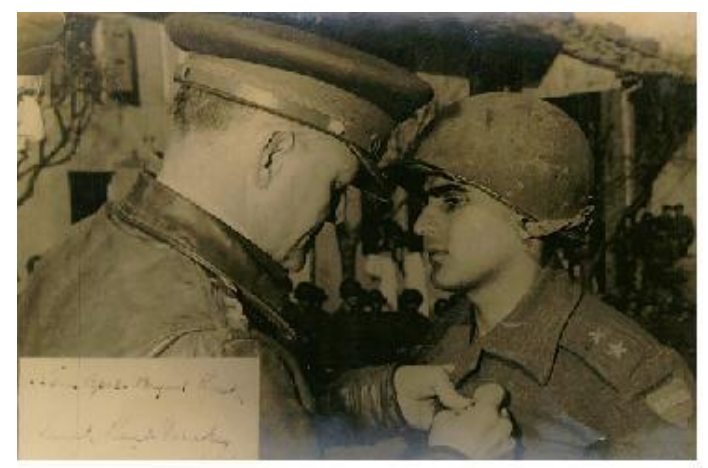

Moyses Chahon, Um...

30.03.45 - Ten R/2 Apollo recebe a "Silver Star"do Cmt do V Exército americano, Gen Lucian Truscott, Lizano de Belvedere, Itália

A citação expedida em Boletim do Quartel General do V Exercito, traduzida do inglês, concede a Silver Star a Moyses por atos de bravura em combate aos 23 de fevereiro de 1945, na conquista do importante objetivo de La Serra, onde sob pesado e constante fogo de artilharia e morteiros conduziu seu pelotão no avanço sobre o ponto cotado 958, expulsando os alemães de posições extremamente bem fortificadas. Confrontando intenso fogo inimigo e repetidos contra-ataques, organizou e manteve a defesa da posição recem-conquistada, ainda que penosamente, dado ter sido ferido ao inicio do engajamento. O Primeiro Tenente Moyses brava e heroicamente liderou os seus soldados na derrota do inimigo. Ingressou no Serviço Militar no Brasil.

Moyses recebeu ainda a Medalha Sangue do Brasil, por ter sido ferido em ação, a Cruz de Combate de 2a. Classe, Medalha de Campanha, Medalha de Guerra, e uma Citação de Combate do General de Divisao João Baptista Mascarenhas de Moraes, Comandante da FEB, expedida aos 23 de fevereiro de 1945, onde se pode ler ao final:

"A combatividade, o espirito de sacrifício, a decisão inquebrantável, a elevada compreensão que tem da honra militar, a capacidade de comando reveladas pelo Ten Chahon, são exemplos dignificantes que desejo por em relevo, para os brasileiros que combatem na Itália”.

Recebeu ainda a Ordem do Mérito Militar de 1a. Classe, Medalha Militar com Passador de Ouro (30 anos), Medalha do Pacificador, e a Carta Patente de Cavaleiro de mérito da Ordem Militar e Hospitalar de são Lazaro de Jerusalém. 
Moyses foi agraciado com a Cruz de Combate de 2. Classe outorgada pelo Presidente d Republica; Em extensa citação no diploma, Moyses é louvado pela coragem com que comandou seu pelotão, mantendo-se por 4 dias em em face de sucessivos e violentos contra-ataques inimigos, sendo atacado a granadas de mão, desabrigado e sob fogo de artilharia e morteiros. Nos dia seguintes melhorou as posições e repeliu diversos contra-ataques, fazendo prisioneiros, tendo seu pelotão sofrido as maiores baixas da companhia.

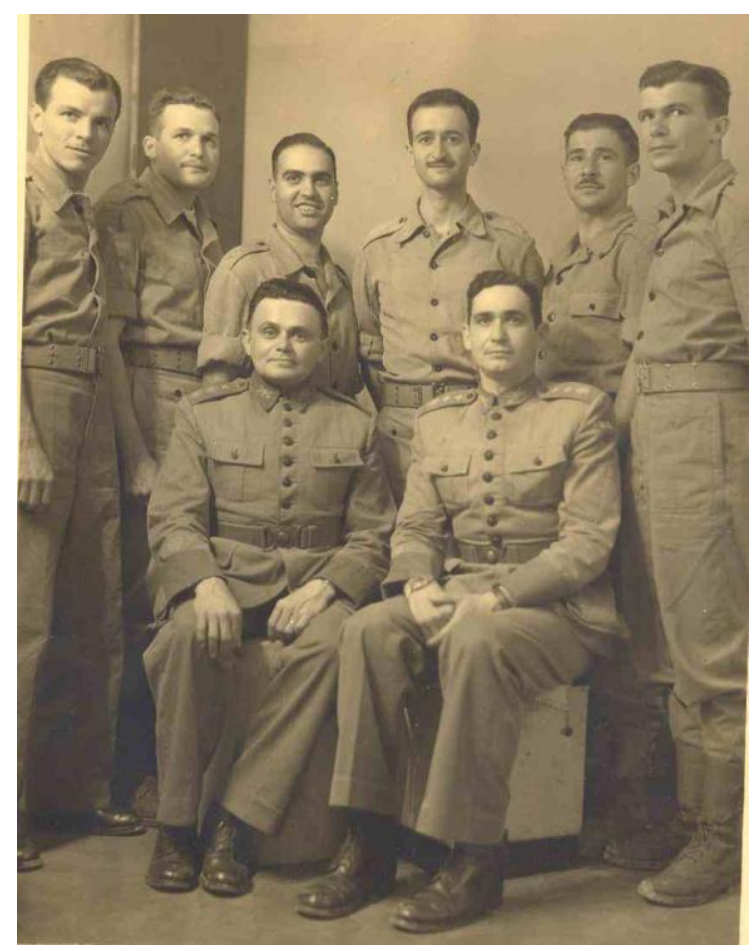

NA foto, Moyses, o $4^{\circ}$. em pé, da esquerda para a direita, aparece junto com outros oficiais. Sentado à esquerda, o futuro Presidente da Republica, o então Ten Cel Castello Branco.

Moyses retornou da Itália em 22 / ago / 1945. Transferido para reserva no posto de General de Divisao aos 25 dez 1969, e reformado em $22 / \mathrm{set} / 1971$.

Moyes Chahon, este bravo Soldado Brasileiro de fé judaica, Herói de La Serra, nos combates da Itália honrou a memória do valente cearense de Tamboril, Brigadeiro Antonio de Sampaio, Patrono da Arma de Infantaria que dá nome ao seu Regimento. Deixou nosso convívio em 1981 aos 63 anos 